Original Research Article

\title{
Drug prescribing patterns in elderly patients in a tertiary level hospital
}

\author{
Nachiket Bhaveshaikh $^{1 *}$, Sangita Sukumaran ${ }^{2}$, Upal Vyas ${ }^{1}$
}

${ }^{1}$ Post Graduate, Department of Pharmacology, Dr. D. Y. Patil Medical College, Navi Mumbai, Maharashtra, India

${ }^{2}$ Professor and Head, Department of Pharmacology, Terna Medical College, Nerul, Navi Mumbai, Maharashtra, India

Received: 25 February 2017 Accepted: 01 March 2017

\section{*Correspondence to:}

Dr. Nachiket Bhaveshaikh, Email: nachiket.bs@gmail.com

Copyright: (C) the author(s), publisher and licensee Medip Academy. This is an openaccess article distributed under the terms of the Creative Commons Attribution NonCommercial License, which permits unrestricted noncommercial use, distribution, and reproduction in any medium, provided the original

\begin{abstract}
Background: Elderly people have multiple co morbidities and are often prescribed potentially inappropriate medications (PIMs). As there is paucity of information about the prescribing practices in elderly this study was undertaken to assess drug utilization patterns in elderly patients.

Methods: A prospective observational study was conducted in a tertiary care hospital. A total of 576 prescriptions of elderly patients were included in the study. Prescribing patterns among elderly patients attending OPD and admitted to wards of departments of Medicine, Psychiatry, Dermatology, Pulmonary Medicine, General Surgery, E.N.T., Ophthalmology, Orthopaedics, Obstetrics and Gynaecology were analysed using the prescribing indicators (WHO criteria). The PIMs were identified as per the Beers 2012 criteria.

Results: The average number of drugs per patient was $3.91 \pm 1.93$ for O.P.D and $7.37 \pm 2.22$ for I.P.D. patients. $37.76 \%$ patients in I.P.D. and $26.87 \%$ patients in O.P.D. received a medication which was potentially inappropriate as per Beers 2012 criteria. $7.58 \%$ (234/3088) of total medications prescribed to patients in the study were potentially inappropriate. There was a significant increase in the number of PIMs ( $p$ value $<0.05$ ) as the total number of drugs prescribed increased.

Conclusions: Educational programmes are needed to reinforce rational prescribing by physicians and precautions should be taken while prescribing potentially inappropriate drugs to elderly patients.
\end{abstract}

Keywords: Beers, Elderly, PIMs, Polypharmacy

\section{INTRODUCTION}

The population of geriatric patients is increasing as a result of increased life expectancy. ${ }^{1}$ The Projected life expectancy in India by 2025 is 69.8 for men and 72.3 for females. $^{2}$

Approximately $80 \%$ of all people above the age of 65 have at least one chronic condition. ${ }^{3}$ As the age of the patient increases the number of comorbidities increases and also the chance of polypharmacy. ${ }^{4}$ Older patients take three times more number of medications as compared to younger patients because of the chronic problems. ${ }^{5}$ Geriatric health care professionals rely heavily on pharmacotherapy as palliative cure for symptoms, and to improve the functional status and quality of life of elderly patients. $^{5}$ Although geriatric patients constitute approximately $13 \%$ of the total population, $30 \%$ of total medication used is prescribed for this age group. ${ }^{6}$ With an increase in the number of medications there is also an increase in adverse effects of the drugs and potentially inappropriate medications. The factors which increase ADRs are polypharmacy, use of CNS medications, anticoagulants and antimicrobials.

Elderly patients show changes in pharmacodynamic parameters such as increased sensitivity to some sedative hypnotic drugs and changes in pharmacokinetic parameters such as decreased capacity of liver to metabolize the drugs and reduced renal function. ${ }^{7}$ Prevalence of multiple co morbidities and inappropriate drug use in elderly causes problems such as drug resistance and adverse effects. ${ }^{8,9}$ Explicit criteria to identify certain drugs as potentially inappropriate medications are developed for elderly patients. The most 
common amongst them are the Beers criteria-which consist of 53 medication classes that need to be avoided in elderly and the STOPP criteria -screening tool of older persons potentially inappropriate Prescriptions comprising of 65 medications, which must be avoided in elderly. ${ }^{10,11}$

The goal of the American geriatric society revised Beers criteria-2012 was to improve care of elderly patients by reducing their exposure to Potentially inappropriate medications. $^{12}$ Early detection of a potentially inappropriate medication can prevent adverse effects. ${ }^{13}$ However not all physicians take them into consideration while prescribing to the elderly. Drug utilization studies in elderly people are scarce. ${ }^{14}$ Elderly people especially those above 85 years of age are underrepresented in clinical trials. ${ }^{3}$ As there is paucity of information about the prescribing practices in elderly this study was undertaken to assess drug utilization patterns in elderly patients

\section{METHODS}

A prospective observational study was conducted in a tertiary care hospital. A total of 576 prescriptions of elderly patients i.e. patients above the age of 65 years were included in the study. Prescribing patterns among elderly patients attending OPD and admitted to wards of departments of Medicine, Psychiatry, Dermatology, Pulmonary Medicine, General Surgery, E.N.T., Ophthalmology, Orthopaedics, Obstetrics and Gynaecology were analysed using the prescribing indicators (WHO criteria).

\section{Inclusion criteria}

- Patients above 65 years of age

- Patients willing to give written informed consent.

\section{Exclusion criteria}

- Patients who are unable to communicate e.g. patients on ventilators,

- Patients who are seriously ill and admitted in the I.C.U.

- $\quad$ Patients visiting O.P.D. for small surgical procedures

- Patients who are unwilling to participate in the study due to any reason.

The study procedure was explained to the patients who volunteered and fulfilled the inclusion criteria. Informed consent was taken from all the patients and prescriptions of suitable patients were collected for this study.

Prescriptions were analysed using WHO prescribing indicators.

- Average number of drugs per prescription (encounter);

- Percentage of drugs prescribed by generic name;
- Percentage of encounters resulting in prescription of an antibiotic;

- Percentage of encounters resulting in prescription of an injection;

- Percentage of drugs prescribed from essential drugs list or formulary;

- The prevalence of adverse drug reactions

Other parameters assessed were as follows:

- Pattern of use of Fixed Dose Combinations in elderly patients

- $\%$ of prescribed drugs which are potentially inappropriate medications (PIM's) as per Beers criteria 2012

- $\%$ of patients prescribed drugs which are to be avoided in elderly as per Beers criteria 2012

\section{Statistical analysis}

Results on continuous measurements are presented on Mean \pm SD (Min-Max) and results on categorical measurements are presented in Number (\%).Data was analyzed using Statistical Package for Social Sciences (SPSS) software version 20. The Pearson's chi square test was used to compare occurrence of PIMs between male and female gender, across various age groups in elderly, and number of drugs prescribed.

\section{RESULTS}

Table 1: Age wise distribution of I.P.D. and O.P.D. patients.

\begin{tabular}{|lll|}
\hline Age (years) & $\begin{array}{l}\text { Number of } \\
\text { patients I.P.D. }\end{array}$ & $\begin{array}{l}\text { Number of } \\
\text { patients O.P.D. }\end{array}$ \\
\hline $65-69$ & 103 & 122 \\
\hline $70-74$ & 66 & 106 \\
\hline $75-79$ & 44 & 71 \\
\hline $80-84$ & 17 & 23 \\
\hline $85-89$ & 9 & 10 \\
\hline $90-94$ & 2 & 3 \\
\hline Total & 241 & 335 \\
\hline
\end{tabular}

\section{W.H.O. core drug indicators-I.P.D. prescriptions}

- The mean age of the patients was $71.87 \pm 6.09$ years (range 65-93 years).

- The average number of drugs per prescription (encounter) was $7.37 \pm 2.22$ (range 2-14).

- $\quad 4.95 \%$ of the drugs given (i.e. 88 drugs out of 1777) were prescribed by the generic name.

- $82.16 \%$ of encounters resulted in prescription of an antibiotic.

- $85.89 \%$ of encounters resulting in prescription of an injection.

- $44.01 \%$ of the prescribed drugs were from the W.H.O. essential drugs list. 
Table 2: Potentially inappropriate medications used in IPD and OPD patients as per the Beers 2012 criteria.

\begin{tabular}{|c|c|c|}
\hline Therapeutic class/ medication & No. of prescriptions OPD & No of prescriptions IPD \\
\hline \multicolumn{3}{|c|}{ 1. Potentially inappropriate medications and classes to avoid in older adults } \\
\hline \multicolumn{3}{|c|}{ Central nervous system and psychotropic drugs } \\
\hline Anticholinergics (trihexyphenidyl) & 5 & - \\
\hline Antihistamines, $1^{\text {st }}$ generation & 10 & 12 \\
\hline Antipsychotics & 12 & 3 \\
\hline Benzodiazepines (short and intermediate acting) & 9 & 6 \\
\hline Benzodiazepines (long acting) & 23 & 3 \\
\hline Nonbenzodiazepines (z) hypnotics & 1 & 1 \\
\hline \multicolumn{3}{|l|}{ Cardiovascular } \\
\hline Amiodarone & 4 & - \\
\hline Nifedipine IR & 4 & 9 \\
\hline Prazosin & - & 1 \\
\hline \multicolumn{3}{|l|}{ Gastrointestinal } \\
\hline GI antispasmodics & 15 & 10 \\
\hline Paraffin ( mineral oil) & 10 & 22 \\
\hline Metoclopramide & & 1 \\
\hline \multicolumn{3}{|l|}{ Analgesics } \\
\hline Indomethacin & 3 & \\
\hline Ketorolac & & 2 \\
\hline \multicolumn{3}{|l|}{ Anti- infective } \\
\hline Nitrofurantoin & - & 1 \\
\hline \multicolumn{3}{|l|}{ Endocrine } \\
\hline Insulin by sliding scale & - & 23 \\
\hline \multicolumn{3}{|l|}{ Skeletal muscle relaxants } \\
\hline Chlorzoxazone & 3 & \\
\hline \multicolumn{3}{|l|}{ Drugs exceeding recommended dose } \\
\hline Digoxin $>0.125 \mathrm{mg} /$ day & 12 & 6 \\
\hline Spironolactone>25mg/day & 7 & 6 \\
\hline \multicolumn{3}{|c|}{ 2. Potentially inappropriate medications and classes to avoid in older adults with certain diseases and syndromes } \\
\hline \multicolumn{3}{|c|}{ Constipation } \\
\hline Pheniramine & & 1 \\
\hline Diltiazem & & 1 \\
\hline \multicolumn{3}{|l|}{ Cardiac failure } \\
\hline Aspirin & & 4 \\
\hline \multicolumn{3}{|l|}{ Seizures } \\
\hline Tramadol & & 1 \\
\hline \multicolumn{3}{|l|}{ History of fall or fracture } \\
\hline Clonazepam & & 1 \\
\hline \multicolumn{3}{|l|}{ Peptic ulcer disease } \\
\hline Diclofenac without gastroprotective agent & & 1 \\
\hline \multicolumn{3}{|l|}{ 3. Drugs to be used with caution in older adults } \\
\hline Aspirin for adults $>80 \mathrm{yrs}$ for primary prevention & 1 & 2 \\
\hline Carbamazepine & 2 & 2 \\
\hline Mirtazepine & 6 & - \\
\hline SNRIs/SSRIs/TCAs & 16 & - \\
\hline Prasugrel & & 1 \\
\hline
\end{tabular}

\section{O.P.D. prescriptions}

- The mean age of the patients was $72.20 \pm 5.68$ years (range 65-91 years).
- The average number of drugs per prescription (encounter) was 3.91 1.93 (range 2-10 drugs).

- Only $1.75 \%$ of the drugs given (i.e.23 drugs out of 1311) were prescribed by generic name. 
- $44.78 \%$ of encounters resulted in prescription of an antibiotic.

- $1.49 \%$ of encounters resulted in prescription of an injection.

- $34.02 \%$ of the prescribed drugs were from the W.H.O. essential drugs list.

Ceftriaxone was the most commonly prescribed antibiotic for I.P.D. patients $(25.31 \%$ patients) while for patients visiting O.P.D. the most common antibiotic was the combination of Amoxicillin+Clavulinic acid (8.96\% patients). Diuretics followed by $\beta$ blockers and Calcium channel blockers were the most commonly prescribed drugs acting on cardiovascular system.

Insulin was prescribed to $16.18 \%$ of I.P.D patients for Diabetes Mellitus. For both I.P.D. and O.P.D. patients Metformin or combination of Metformin and Sulfonylureas was the preferred drug for Diabetes.

Pantoprazole was the most commonly used agent for treatment of peptic ulcer in I.P.D (60.17\% patients) as well as O.P.D. patients (21.49\% patients). No major drug- drug interactions were reported. No serious adverse drug events were reported. 15 patients however had adverse effects to their medications which were expected adverse effects of the drugs used.

\section{Drugs used in IPD patients}

The number of PIMs seen was highest (52/116) in medicine department. However, all the patients in psychiatry department received at least 1 PIM.

\section{Drugs used in OPD patients}

The maximum number of PIMs was seen in department of psychiatry where more than $80 \%$ patients received at least 1 PIM.

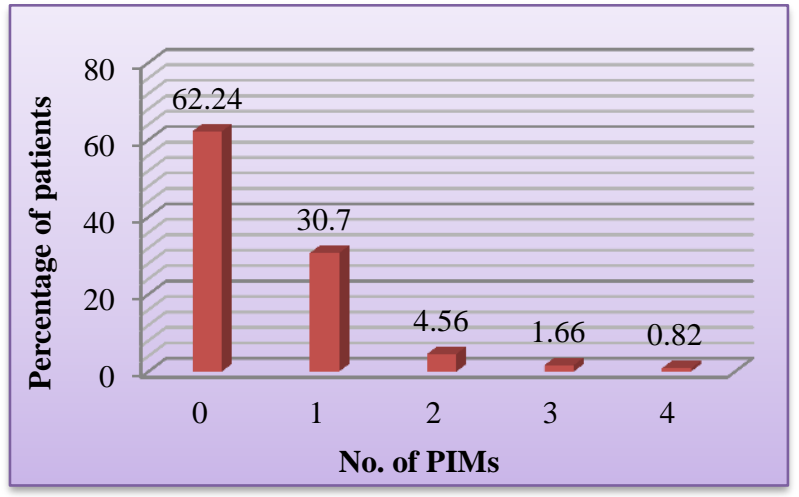

Figure 1: Percentage of I.P.D. patients with PIMs as per Beers criteria.

$37.76 \%$ patients in I.P.D. and $26.87 \%$ patients in O.P.D. received a medication which was potentially inappropriate as per Beers 2012 criteria. 7.58\%
(234/3088) of total medications prescribed to patients in the study were potentially inappropriate. 62.24\% IPD patients did not receive any PIM. 30.70\% received 1 PIM and $7 \%$ of patients received 2 or more PIMs respectively.

More than $60 \%$ of patients over the age of 80 received at least 1 PIM where as less than $35 \%$ patients between age groups of 60-69 and 70-79 received PIMs.

Table 3: PIMs as per age of patients in I.P.D. patients.

\begin{tabular}{|lll|}
\hline $\begin{array}{l}\text { Age } \\
\text { group }\end{array}$ & $\begin{array}{l}\text { Number of cases } \\
(\%)\end{array}$ & $\begin{array}{l}\text { Number of patients } \\
\text { receiving PIMs }(\%)\end{array}$ \\
\hline $60-69$ & $103(42.73)$ & $36(34.95)$ \\
\hline $70-79$ & $110(45.64)$ & $38(34.55)$ \\
\hline $80+$ & $28(11.61)$ & $17(60.71)$ \\
\hline Total & $241(100)$ & 91 \\
\hline
\end{tabular}

There was a statistical difference ( $p$ value $<0.05$ ) between the age groups and number of PIMs

Table 4: PIMs as per Gender in I.P.D. patients.

\begin{tabular}{|lll|}
\hline Sex & $\begin{array}{l}\text { Number of cases } \\
(\%)\end{array}$ & $\begin{array}{l}\text { Number of patients } \\
\text { receiving PIMs }(\%)\end{array}$ \\
\hline Male & $124(51.54)$ & $51(41.13)$ \\
\hline Female & $117(48.55)$ & $40(34.18)$ \\
\hline Total & $241(100)$ & 91 \\
\hline
\end{tabular}

$41.13 \%$ males and $34.18 \%$ females received PIMs. There was no statistical difference ( $\mathrm{p}$ value $>0.05$ ) between sex of patients and PIMs they received.

Table 5: PIMs as per number of drugs in I.P.D. patients.

\begin{tabular}{|lll|}
\hline $\begin{array}{l}\text { No. of drugs } \\
\text { Prescribed }\end{array}$ & $\begin{array}{l}\text { No. of cases } \\
(\%)\end{array}$ & $\begin{array}{l}\text { No. of patients } \\
\text { receiving PIMs (\%) }\end{array}$ \\
\hline $1-6$ & $88(36.51)$ & $21(23.86)$ \\
\hline $7-10$ & $130(53.94)$ & $53(40.76)$ \\
\hline$>11$ & $23(9.54)$ & $17(73.91)$ \\
\hline Total & $241(100)$ & 91 \\
\hline
\end{tabular}

$73.91 \%$ patients (17/23 patients) who were prescribed more than 11 drugs received a PIM. $40.76 \%$ patients (53/130 patients) who were prescribed between 7-10 drugs received a PIM. Only $23.86 \%$ patients $(21 / 88$ patients) who were prescribed less than 7 drugs received a PIM. There was a significant increase in the number of PIMs $(\mathrm{P}<0.05)$ as the number of drugs prescribed to a patient increased (Table 5). $73.13 \%$ patients attending OPD didn't receive any PIM. $19.40 \%$ received 1 PIM. Only $7.46 \%$ patients received 2 or more PIMs.

$36.11 \%$ patients above the age of 80 years received a PIM. $31.14 \%$ patients between ages of $60-69$ years received a PIM and $22.03 \%$ patients between $70-79$ years received a PIM. 
Table 6: PIMs as per age of patients in O.P.D. patients.

\begin{tabular}{|lll|}
\hline $\begin{array}{l}\text { Age } \\
\text { group }\end{array}$ & No. of cases $(\%)$ & $\begin{array}{l}\text { No. of patients } \\
\text { receiving PIMs (\%) }\end{array}$ \\
\hline $60-69$ & $122(36.41)$ & $38(31.14)$ \\
\hline $70-79$ & $177(52.84)$ & $39(22.03)$ \\
\hline $80+$ & $36(10.75)$ & $13(36.11)$ \\
\hline Total & $335(100)$ & 90 \\
\hline
\end{tabular}

There was a statistical difference $(p$ value $<0.05)$ between the age groups of the patients and PIMs.

Table 7: PIMs as per gender in OPD patients.

\begin{tabular}{|lll|}
\hline Sex & No. of cases $(\%)$ & $\begin{array}{l}\text { No. of patients } \\
\text { receiving PIMs (\%) }\end{array}$ \\
\hline Male & $172(51.34)$ & $47(27.32)$ \\
\hline Female & $163(48.66)$ & $43(26.38)$ \\
\hline Total & $335(100)$ & 90 \\
\hline
\end{tabular}

There was no statistical difference ( $\mathrm{p}$ value $>0.05$ ) between sex of the patients and PIMs.

Table 8: PIMs as per the number of drugs prescribed in OPD patients.

\begin{tabular}{|lll|}
\hline $\begin{array}{l}\text { No. of drugs } \\
\text { prescribed }\end{array}$ & $\begin{array}{l}\text { No. of } \\
\text { cases }(\%)\end{array}$ & $\begin{array}{l}\text { No. of patients } \\
\text { receiving PIMs (\%) }\end{array}$ \\
\hline $1-6$ & $303(90.45)$ & $65(21.45)$ \\
\hline $7-10$ & $32(9.55)$ & $25(78.12)$ \\
\hline $11+$ & $0(0)$ & $0(0)$ \\
\hline Total & $335(100)$ & 90 \\
\hline
\end{tabular}

There was a significant increase in the number of PIMs ( $\mathrm{p}$ value $<0.05)$ as the total number of drugs prescribed increased.

$21.5 \%$ receiving between 1-6 drugs were prescribed PIMs. Out of this $16.2 \%$ patients received $78.12 \% 1$ PIM where as $5.28 \%$ received more than 2 PIMs. PIM (Table 8) patients receiving more than 6 drugs received. In this group 50\% patients received 1 PIM and $28.13 \%$ received more than 2 PIMs.

\section{DISCUSSION}

Drug therapy is most common and important treatment in elderly people. Most geriatric patients take medications for long durations to control chronic conditions such as diabetes, hypertension, heart failure etc. Drugs are also used for shorter periods for symptomatic relief from conditions such as pain, to treat infections and prophylactically to prevent diseases.

A majority of the patients in our study were admitted to the departments of medicine $(27.78 \%$ patients $)$ and surgery ( $24.50 \%$ patients). This trend is similar to studies done in elderly patients in India and in Nepal. ${ }^{15,16}$ The age group of 65-74 years had the highest number of patients $(68.75 \%)$; whereas only $4.17 \%$ patients were above 85 years. These trends in age group patterns are comparable to similar a study done in India. ${ }^{17}$

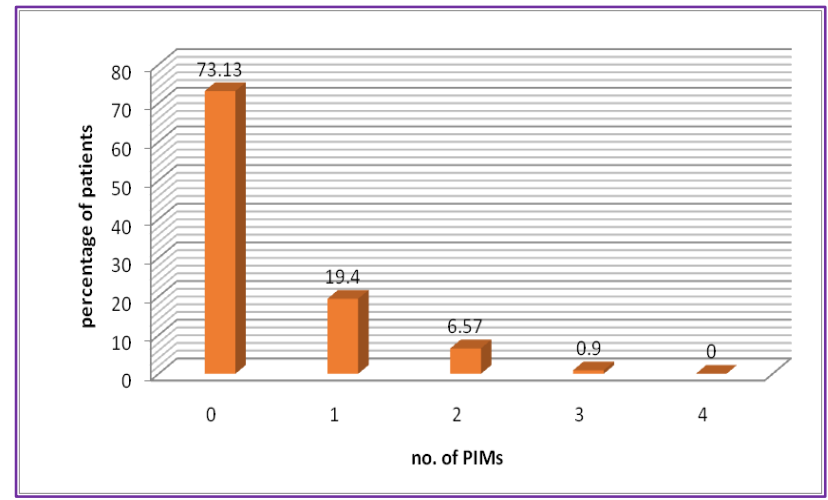

Figure 2: Percentage of O.P.D. patients with PIMs as per Beers criteria.

The average number of drugs per patient was $3.91 \pm 1.93$ for O.P.D comparable with 4.25 drugs in other similar study in O.P.D. patients by Zaveri et al. ${ }^{16}$ The average number of drugs used was $7.37 \pm 2.22$ for I.P.D. patients. This was comparable to two similar studies. ${ }^{17,18}$ where average number of drugs in elderly patients in I.P.D. was 7.30 and 7.73 respectively. This was lower than 9.52 drugs as per a study by Momin et al and 8.42 per patients as per a study done in the Bangalore. ${ }^{1,19,20}$ The difference could be because the studies were done only in medicine wards where comparatively higher number of drugs are used where as our study included all other departments as well.

$10.82 \%$ of the formulations used in our study were FDCs. Use of F.D.C.s results in an underestimation of actual number of drugs prescribed. The average drugs per patient would go up by more than $13 \%$ for O.P.D. and $9 \%$ for I.P.D. patients if the individual contents of fixed dose combination drugs were taken into account. In elderly with renal and hepatic dysfunction, F.D.C.s may lead to unnecessary and prolonged exposure to drugs and increase risk of toxicity. ${ }^{15}$

Less than $40 \%$ of total drug formulations were from the essential drug list. This is similar to $44 \%$ use of essential drugs by a study done in Bhavnagar. ${ }^{19}$ The total number of drugs prescribed by generic name was less than $5 \%$. This was significantly lower than $36.8 \%$ in a study done by Shankar et al and $48.79 \%$ in another study in elderly done by Jhaveri et al. ${ }^{18,19}$ There is need to reinforce prescribing drugs by generic name as this will ultimately lead to rational use of drugs and reduce the cost to the patients. $^{17}$

Based on Beers criteria 2012, 118 out of 1311 (9\%) of the drugs prescribed in O.P.D. were inappropriate. 90 $(26.87 \%)$ of patients received at least 1 PIM. This is similar to a study done in elderly patients in medicine out-patient department in India where $7.42 \%$ of drugs prescribed were inappropriate and $23.58 \%$ patients received at least one inappropriate drug. ${ }^{16} 116$ out of the total $1777(6.53 \%)$ drugs prescribed in wards were inappropriate and $91(37.76 \%)$ patients received at least 1 
PIM. The trend is similar to a study in elderly patients where $27.25 \%$ patients received one PIM and $4.65 \%$ drugs were inappropriate. ${ }^{17}$

As the total number of drugs prescribed to patients increased there was a statistically significant increase in the number of PIMs received. There should also be mass awareness amongst physicians about rational use of drugs. Educational programmes are needed to reinforce rational prescribing by physicians. Care should be taken while prescribing potentially inappropriate drugs to elderly patients and any adverse effects should be identified at earliest.

\section{Funding: No funding sources}

Conflict of interest: None declared

Ethical approval: The study was approved by the Institutional Ethics Committee

\section{REFERENCES}

1. Momin TG, Pandya RN, Rana DA, Patel VJ. Use of potentially inappropriate medications in hospitalized elderly at a teaching hospital: a comparison between Beers 2003 and 2012 criteria. Indian J Clinic Pharmacol. 2013;45(6):603-7.

2. National health profile. Report of the Technical Group on Population Projections. National Commission on Population/MOHFW/GOI. 2010. Available from: www.cbhidghs.nic.in/writereaddata/mainlinkFile/File 1131.pdf

3. Jackson S, Jansen P, Mangoni A. Prescribing for elderly patients. Clinical Pharmacology of Ageing. $1^{\text {st }}$ edition. John Wiley and Sons, Wiley-Blackwell; 2009:1-12.

4. Amann U, Schmedt N, Garbe E. Prescribing of potentially inappropriate medications for the elderly: an analysis based on the PRISCUS list. Dtsch Arztebl Int. 2012;109(5):69-75.

5. Fillit HM, Rockwood K, Woodhouse K. Broklehurst's textbook of geriatric medicine and gerontology. Saunders Elsevier. 7th edition. 2010.

6. Kutsal Y. Polypharmacy in elderly. Turk Geriatri Dergisi. 2006;9:37-44.

7. Katzung BG, Masters SB, Trevor AJ. Basic and clinical pharmacology. 11th ed. Tata Mcgrow hill 2009.1037-46.

8. Arslan S, Atalay A, Kutsal YG. Drug use in elderly. Turk Geriatri Dergisi. 2000; 3(2):56-60.

9. Hajjar ER, Cafiero AC, Hanlon JT. Polypharmacy in elderly patients. Am J Geriatr Pharmacoth. 2000;5(4):345-51.

10. Campanelli CM. American geriatrics society updated beers criteria for potentially inappropriate medication use in older adults. $\mathbf{J}$ Am Geriatr Soc. 2012;60(4):616-31.

11. Mahony DO, Gallagher P, Ryan C, Byrne S, Hamilton H, Barry P, Connor MO, Kennedy J. STOPP and START criteria: a new approach to detecting potentially inappropriate prescribing in old age. Europ Geriat Medic. 2010;1:45-51.

12. Askari M, Wierenga PC, Eslami S, Medlock S, deRooij SE, Abu-Hanna A. Assessing quality of care of elderly patients using the ACOVE quality indicator set: a systematic review. Plos one. 2011;6:1-7.

13. Tangiisuran B, Wright JE, Van der Cammen TJM, Rajkumar C. Adverse drug reactions in the elderly: challenges in identification and improving preventative strategies. Age Ageing. 2009;38:358-9.

14. Bakken MS, Ranhoff AH, Engeland A, Ruths S. Inappropriate prescribing for older people admitted to an intermediate-care nursing home unit and hospital wards. Scand J Prim Health Care. 2012;30:169-75.

15. Shankar PR, Upadhyay DK, Subish P, Bhandari RB, Das B. Drug utilisation among older inpatients in a teaching hospital in Western Nepal. Singapore Med J. 2010;51(1):28-34.

16. Zaveri HG, Mansuri SM, Patel VJ. Use of potentially inappropriate medicines in elderly: a prospective study in medicine out-patient department of a tertiary care teaching hospital. Indian $\mathbf{J}$ Pharmacol. 2010;42:95-8.

17. Shah RB, Gajjar BM, Desai SV. Evaluation of the appropriateness of prescribing in geriatric patients using beers criteria and phadke's criteria and comparison thereof. J Pharmacol Pharma Co The R. 2011;2(4):248-52.

18. Shankar PR, Upadhyay DK, Subish P, Bhandari RB, Das B. Drug utilisation among older inpatients in a teaching hospital in Western Nepal. Singapore Med J. 2010; 51(1):28-34.

19. Jhaveri BN, Patel TK, Barvaliya MJ, Tripathi CB. Drug utilization pattern and pharmacoeconomic analysis in geriatric medical in-patients of a tertiary care hospital of India. J Pharmacol Pharmacother. 2014;5(1):15-20.

20. Razavi M, Meera NK, Karimian H, Khajuria DK. A profile of drug utilization among elderly inpatients admitted at a tertiary level hospital in Bangalore: a prospective study. Archives of Pharmacy Practice. 2012;3(3):217-22.

Cite this article as: Bhaveshaikh N, Sukumaran S, Vyas U. Drug prescribing patterns in elderly patients in a tertiary level hospital. Int $\mathrm{J}$ Basic Clin Pharmacol 2017;6:759-64 